\title{
Numerical and Experimental Modal Control of Flexible Rotor Using Electromagnetic Actuator
}

\author{
Edson Hideki Koroishi, Adriano Silva Borges, \\ Aldemir Ap Cavalini Jr., and Valder Steffen Jr. \\ School of Mechanical Engineering, Federal University of Uberlândia, Avenue João Naves de Ávila 2121, \\ Campus Santa Mônica, Uberlândia 38408-100, MG, Brazil \\ Correspondence should be addressed to Valder Steffen Jr.; vsteffen@mecanica.ufu.br
}

Received 11 February 2014; Revised 31 March 2014; Accepted 31 March 2014; Published 30 April 2014

Academic Editor: Weichao Sun

Copyright (C) 2014 Edson Hideki Koroishi et al. This is an open access article distributed under the Creative Commons Attribution License, which permits unrestricted use, distribution, and reproduction in any medium, provided the original work is properly cited.

\begin{abstract}
The present work is dedicated to active modal control applied to flexible rotors. The effectiveness of the corresponding techniques for controlling a flexible rotor is tested numerically and experimentally. Two different approaches are used to determine the appropriate controllers. The first uses the linear quadratic regulator and the second approach is the fuzzy modal control. This paper is focused on the electromagnetic actuator, which in this case is part of a hybrid bearing. Due to numerical reasons it was necessary to reduce the size of the model of the rotating system so that the design of the controllers and estimator could be performed. The role of the Kalman estimator in the present contribution is to estimate the modal states of the system and to determine the displacement of the rotor at the position of the hybrid bearing. Finally, numerical and experimental results demonstrate the success of the methodology conveyed.
\end{abstract}

\section{Introduction}

Currently, it is observed an increasing number of research works in engineering devoted to the development of new active vibration control techniques (AVC). Among the wellknown techniques for AVC, nowadays, active vibration modal control (AVMC) is a highlight and present successful applications in several areas [1-5].

Modal control uses the modal states for controlling purposes. Normally, these modal states are not directly accessible in the experiment. For this reason, state estimators can be employed to determine the modal states. The use of estimators requires a reduction of the model according to the number of considered modes for controlling the system. However, the use of reduced models can generate spillover effects, which can be overcome by choosing appropriate number and position of actuators and sensors [6].

Modal controllers can be designed by using various approaches, namely, optimal control (LQR, LQG) [7], robust control $\left(H_{\infty}\right.$ norm) [8], or fuzzy logic [9]. Optimal and robust controls are characterized by controllers with fixed gain matrix, which are obtained from the model of the system.
However, for structures with nonlinear behavior, whose characteristics change considerably with respect to time, these methods lead to several controllers that should operate simultaneously (parallel compensation). For nonlinear structures, the fuzzy logic controller has shown to be better adapted since it does not require a model of the system.

In terms of rotating machines, there are various types of actuators available, such as hydraulic rotary actuators, piezoelectric stack actuators, active magnetic bearings (AMB), and electromagnetic actuators (EMA). Hydraulic rotary actuators have the advantage of small size-to-power ratios and large force/torques output, being appropriate for heavy machinery [10]. The piezoelectric actuators demonstrated to be very effective in rotor vibration control [11]. More recently [7] used PZT stack actuators for active modal control of flexible rotors. The PZT actuator is attached directly to the ball bearing, which allows the insertion of stiffness to the system. The AMB are used both in the support and in the control of rotors, through the application of lateral forces without mechanical contact between the rotor and the stator. They have been successfully applied to industrial turbo machines 
[12]. However, AMBs have some disadvantages, namely, technical complexity and continuous power consumption [13]. This continuous power consumption is due to rotor support requirements. Some improvements of AMBs technologies were proposed in [14]. The EMA uses the same principle of $\mathrm{AMB}$, but only in terms of lateral contactless forces, since EMA is not used to support the rotor. The use of EMA results normally in a hybrid bearing [15]. There are many applications of EMA in AVC, such as the control of light structures [16], the attenuation of the oil whip instability effect to flexible hydrodynamically supported rotors [17], and the vibration attenuation using a tilting-pad journal bearing [18]. The main advantage of EMA is related to its simple electromechanical structure associated with a control action that is performed without mechanical contact.

In the present contribution the active vibration modal control is tested both numerically and experimentally. As mentioned before, two different approaches are studied, namely, the linear quadratic regulator (LQR) and the fuzzy logic controller (FLC). In both cases the modal displacements and modal velocities are used by the controllers to determine the control force. The LQR was solved by linear matrix inequalities (LMIs). The LMIs include an optimization approach to determine the gains of the controllers so that uncertainties can be taken into account. The FLCs were found to be well adapted for controlling structures with nonlinear behavior, whose characteristics change considerably with respect to time. Since the modal states cannot be accessed directly during experimentation, they have to be rebuilt by using an estimator algorithm. Consequently, for determining the modal states, the Kalman estimator was chosen. As an important characteristic, this estimator can rebuild the modal states from noisy signal responses. As mentioned above, numerical and experimental results are presented to illustrate the proposed methodology. The simulations are performed so that the procedure is as similar as possible of the experimental conditions. The electromagnetic actuators are used to apply the control force to attenuate the vibration along the two lateral directions of the rotor.

The aim of this work is to study the effectiveness of the controller to attenuate vibration by using two different approaches for active modal vibration control, namely, the linear quadratic regulator and the fuzzy logic controller. In a previous contribution [19] control techniques dedicated to rotor dynamics were investigated by using only numerical simulation results. However, in the present work, the control techniques were effectively tested on an experimental rotor test rig aiming at validating the control strategies proposed. This work is divided in five parts, as follows: after a brief introduction, the rotor model is defined by using the finite element method (FEM); the characteristics of the electromagnetic actuator are presented; the control approach and the architecture of the control system are discussed; numerical and experimental results are performed for the unbalance response; finally, conclusions are summarized.

\section{System Modeling}

The models used to represent the complete control system are presented separately. First, the rotor formulation and its properties are shown. In the following, the general characteristics

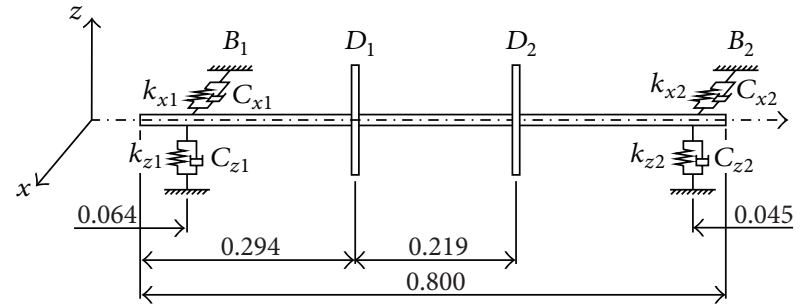

FIGURE 1: Scheme of rotor.

and properties of the electromagnetic actuators are discussed. Finally, the pseudomodal method is revisited and the reduced model is presented so that the design of the controller and estimator can be done.

2.1. Rotor Model. The dynamic response of the considered mechanical system can be modeled by using principles of variational mechanics, namely, Hamilton's principle. For this aim, the strain energy of the shaft and the kinetic energies of the shaft and discs are calculated. An extension of Hamilton's principle makes it possible to include the effect of energy dissipation. The parameters of the bearings are included in the model by using the principle of the virtual work. For computation purposes, the finite element method is used to discretize the structure so that the energies calculated are concentrated at the nodal points. Shape functions are used to connect the nodal points. To obtain the stiffness of the shaft, Timoshenko's beam theory was used and the cross-sectional area was updated. The model obtained as described above is represented mathematically by a set of differential equations [22] as given by

$$
\begin{aligned}
& {[M]\{\ddot{\delta}(t)\}+\left[C_{b}+\dot{\phi} C_{g}\right]\{\dot{\delta}(t)\}+\left[K+\phi K_{g}\right]\{\delta(t)\}} \\
& =\{F(t)\}+\left\{F_{\mathrm{EMA}}(t)\right\}
\end{aligned}
$$

where $\{\delta(t)\}$ is the vector of generalized displacements; $[M]$, $[K],\left[C_{b}\right],\left[C_{g}\right]$, and $\left[K_{g}\right]$ are the well-known matrices of inertia, stiffness, bearing viscous damping (that may include proportional damping), gyroscopic effect (with respect to the speed of rotation), and the effect of the variation of the rotation speed; $\dot{\phi}$ is the time-varying angular speed and $\{F(t)\}$ and $\left\{F_{\mathrm{EMA}}(t)\right\}$ are the forces due to the unbalance and the electromagnetic actuators, respectively.

The finite element model considers 4 dof per node, namely, two displacements and two rotations along the $x$ and $z$ directions. The model shown on Figure 1 was discretized using 33 nodes. In this model, the electromagnetic actuator is positioned as close as possible to the bearing $B_{2}$ (node no. 4 ). For the simulation, the excitation force is applied at disk $D_{1}$ (node no. 13). The displacements at nodes number 8 and number 27 are calculated (corresponding to the positions of the sensors of the experimental test rig that is used in the present work).

The properties of bearings were determined experimentally in previous works. These properties together with the rotor properties are presented in Table 1. 
TABLE 1: Physical characteristics of the rotor-bearing system.

\begin{tabular}{lccc}
\hline Characteristic & Value & Characteristic & Value \\
\hline Rotor & \multicolumn{3}{c}{ Bearings } \\
Mass of shaft $(\mathrm{kg})$ & 4.1481 & $k_{x 1}(\mathrm{~N} / \mathrm{m})$ & $7.73 \times 10^{5}$ \\
Mass of disc $\mathrm{D}_{1}(\mathrm{~kg})$ & 2.6495 & $k_{z 1}(\mathrm{~N} / \mathrm{m})$ & $1.13 \times 10^{5}$ \\
Mass of disc $\mathrm{D}_{2}(\mathrm{~kg})$ & 2.6495 & $k_{x 2}(\mathrm{~N} / \mathrm{m})$ & $5.51 \times 10^{8}$ \\
Thickness of $\mathrm{D}_{1}(\mathrm{~m})$ & 0.1000 & $k_{z 2}(\mathrm{~N} / \mathrm{m})$ & $7.34 \times 10^{8}$ \\
Thickness of $\mathrm{D}_{2}(\mathrm{~m})$ & 0.1000 & $C_{x 1}(\mathrm{~N} \cdot \mathrm{s} / \mathrm{m})$ & 5.7876 \\
Diameter of shaft $(\mathrm{m})$ & 0.0290 & $C_{z 1}(\mathrm{~N} \cdot \mathrm{s} / \mathrm{m})$ & 12.6001 \\
Young modulus $\left(\mathrm{GN} / \mathrm{m}^{2}\right)$ & 205 & $C_{x 2}(\mathrm{~N} \cdot \mathrm{s} / \mathrm{m})$ & 97.0231 \\
Density $\left(\mathrm{Kg} / \mathrm{m}^{3}\right)$ & 7850 & $C_{z 2}(\mathrm{~N} \cdot \mathrm{s} / \mathrm{m})$ & 77.8510 \\
Poisson coefficient & 0.3 & & \\
\hline
\end{tabular}

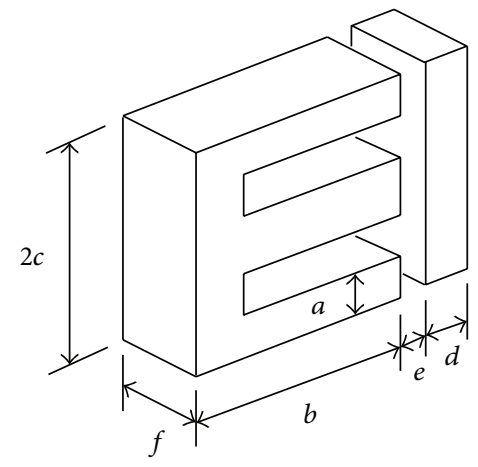

Figure 2: Ferromagnetic circuit [23].

2.2. Electromagnetic Actuator. The EMA is used to apply the control force to the rotor system. The forces provided by the EMA are inversely proportional to the square of the sum of nominal gap and displacement [16]. With these characteristics, each coil applies a force that is given by

$$
F_{\mathrm{EMA}}=\frac{N^{2} I^{2} \mu_{0} a f}{2\left((e+\gamma)+\left((b+c+d-2 a) / \mu_{r}\right)\right)^{2}} .
$$

The parameters that define the geometry of the coils $(a, b$, $c, d$, and $f$ ) are shown in Figure $3 ; \mu_{0}$ and $\mu_{r}$ are the magnetic permeability in the vacuum and the relative permeability of the material, respectively. $\mu_{r}$ is determined experimentally using a methodology proposed by [15]. The nominal gap is given by $e$ and $\gamma$ is the gap due to the vibration of the rotor at the position of the electromagnetic actuator.

The EMA applies only attraction forces and each actuator acts separately. The ferromagnetic circuit used by each actuator is presented in Figure 2. The proposed geometry was studied previously by [23]. The geometry and properties that have been experimentally obtained in previous works are presented in Table 2.

Four EMAs are used in the system, that is, two for each control direction ( $x$ and $z$ ). Figure 3 presents the hybrid bearing (that contains the EMAs) that was designed for the present research work.

2.3. Pseudomodal Method. The use of a larger number of degrees of freedom (dof) results in a high computational cost. Normally it is desirable to reduce the size of the model. There are several methods that can be used for this aim [22]; however, the pseudomodal method is used in the present paper to reduce the model size. The reduction is achieved by changing from the physical coordinates $\{x(t)\}$ to modal coordinates $\{q(t)\}$ as follows:

$$
\{\delta(t)\}=[\Phi]\{q(t)\},
$$

where $[\Phi]$ is the modal basis that contains the $m$ first modes of the nongyroscopic conservative associated system.

By using the transformation given by (3) in (1) and by converting the new set of differential equations to the spacestate form, this results in

$$
\begin{aligned}
\{\dot{X}(t)\} & =[A]\{X(t)\}+\left[B_{w}\right]\{F(t)\}+\left[B_{u}\right]\left\{F_{\mathrm{EMA}}(t)\right\} \\
\{y(t)\} & =[C]\{X(t)\}
\end{aligned}
$$

where

$$
\begin{aligned}
& \{X(t)\}=\{\{q(t)\}\}, \\
& {[A]=\left[\begin{array}{c}
0 \\
-\left[[\Phi]^{T}[M][\Phi]\right]^{-1}\left[[\Phi]^{T}[K][\Phi]\right]-\left[[\Phi]^{T}[M][\Phi]\right]^{-1}\left[[\Phi]^{T}[C][\Phi]\right]
\end{array},\right.} \\
& {\left[B_{w}\right]=\left[\begin{array}{c}
0 \\
{\left[[\Phi]^{T}[M][\Phi]\right]^{-1}[\Phi]^{T}}
\end{array}\right]} \\
& {\left[B_{u}\right]=\left[\begin{array}{c}
0 \\
{\left[[\Phi]^{T}[M][\Phi]\right]^{-1}[\Phi]^{T}}
\end{array}\right]} \\
& {[C]=[[\Phi]] \text {. }}
\end{aligned}
$$


TAble 2: Parameters of the coil.

\begin{tabular}{lc}
\hline$\mu_{0}(\mathrm{H} / \mathrm{m})$ & $1.26 \times 10^{-06}$ \\
$\mu_{r}$ & 700 \\
$N$ (spires) & 250 \\
$a(\mathrm{~mm})$ & 9.50 \\
$b(\mathrm{~mm})$ & 38.0 \\
$c(\mathrm{~mm})$ & 28.5 \\
$d(\mathrm{~mm})$ & 9.50 \\
$f(\mathrm{~mm})$ & 22.5 \\
$e(\mathrm{~mm})$ & 0.5 \\
\hline
\end{tabular}

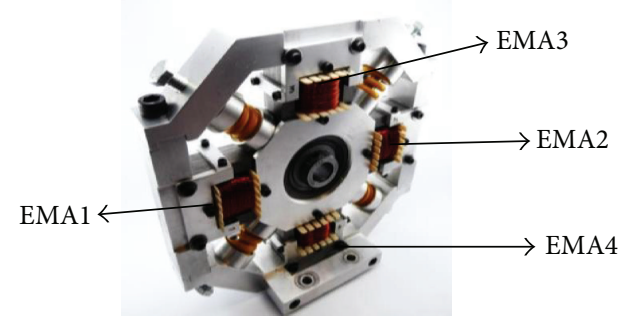

FIGURE 3: Hybrid bearing.

The system presented in (4) was used both in the design of the controller gains through LMIs and in the design of the estimator gain. The number of considered modes is defined according to the controllability and observability of the system represented by (4). In this work the number of modes considered is four (two for each direction of control effort) so that the system is controllable and observable.

\section{Control Approach}

Active modal control is used as control strategy for a rotor system in which an electromagnetic actuator provides the control effort as shown in Figure 4. The advantage of using active modal control is that this technique is very effective for flexible structures applications, requiring a reduced number of actuators and sensors. The estimator is responsible for determining the modal states required by the controllers. The Kalman estimator is able to estimate the states by using noise contaminated measurement signals. In a previous paper [21] used the modal estimation to calculate the air gap at the node, where the EMA is located and a general control strategy was proposed as shown in Figure 4. In the present contribution, this control strategy uses the Kalman estimator performing two different roles: the first is to work as a filter of the dynamic response of the system and the second (and most important function in this case) is to estimate the states and the displacement of the system at the actuator's position. The states are then used by the controllers to determine the control force. As the air gap in the EMA is very small (it is not feasible to insert sensors) the displacement at the actuator's position has to be estimated by the Kalman estimator.

Figure 4 shows that in the modal state feedback control a number of controllers are required. Two types of controllers are used and compared in this work. Both methods require

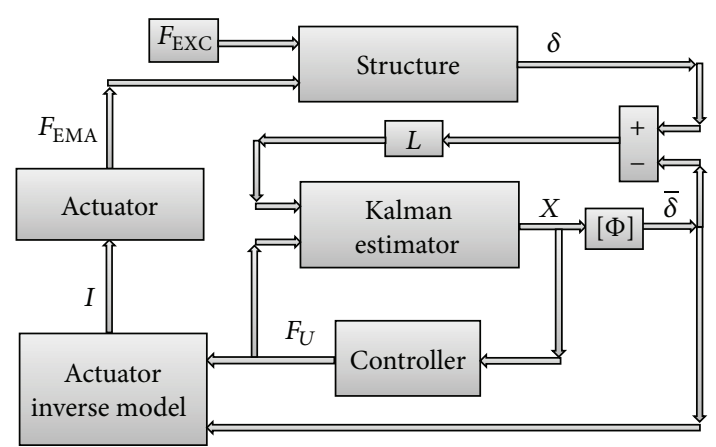

FIgURE 4: Active modal control based on modal state feedback control, adapted from [21].

the modal displacements and modal velocities to determine the control effort of the controllers. The first method uses the linear quadratic regulator, solved by LMIs, for determining the gains of the controllers; the second method is based on fuzzy modal controller.

These methods permit taking into account slight nonlinearities and uncertainties due to the experimental procedures. The difference between the two control strategies is that in the first one (LQR controller) the gain of the controller is determined by taking into account all the modes and there is only one controller for all modes, while in the second (FMC) there is one controller for each mode considered.

The two types of controllers used are presented in Figure 5.

3.1. Linear Quadratic Regulator Solved by LMIs. In this case the control force is given by

$$
F_{u}=-\left[K_{G}\right]\{X(t)\},
$$

where

$$
\left[K_{G}\right]=\left[\left[K_{G q}\right]\left[K_{G \dot{q}}\right]\right] .
$$

Substituting (6) into (8),

$$
\begin{aligned}
\{\dot{X}(t)\} & =\left[[A]-\left[K_{G}\right]\left[B_{u}\right]\right]\{X(t)\}+\left[B_{w}\right]\{F(t)\}, \\
\{y(t)\} & =[C]\{X(t)\} .
\end{aligned}
$$

In (8), the matrix $\left[A_{C}\right]=\left[[A]-\left[K_{G}\right]\left[B_{u}\right]\right]$ is the controllability matrix. The controller gain is determined by using the controllability matrix and solving the following LMIs:

$$
\begin{gathered}
{[A][P]-\left[B_{u}\right][G]+[P][A]^{T}-[G]^{T}\left[B_{u}\right]^{T}+2 \alpha[P]<0,} \\
{[P]>0,}
\end{gathered}
$$

where $[P]$ is a positive definite matrix and $[G]=\left[K_{G}\right][P]$.

And the gain matrix is given by

$$
\left[K_{G}\right]=[G][P]^{-1} .
$$




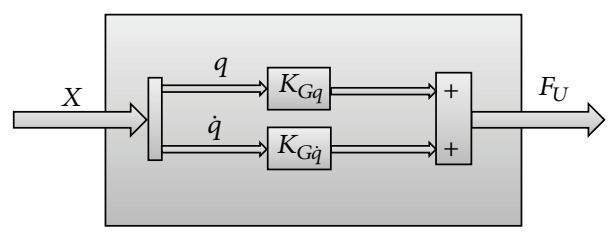

(a)

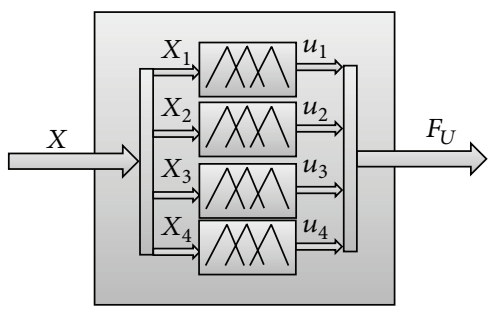

(b)

FIGURE 5: Structure of the controllers: (a) gains determined by LMIs and (b) fuzzy modal controllers. LMIs.

Equation (10) presents the controller's gain by using only

Several authors have considered applications of LQR; however, not so many discuss the LMI version of this controller [24]. A version of LQR solved by LMIs is presented in [25]. The authors of this contribution show that the problem LQR-LMI is described by

$$
\begin{aligned}
\min _{X, P_{\mathrm{lmi}}, X_{\mathrm{lmi}}} \operatorname{tr} & \left(\left[Q_{\mathrm{lqr}}\right]\left[P_{\mathrm{lmi}}\right]\right)+\operatorname{tr}\left(\left[X_{\mathrm{lmi}}\right]\right) \\
& +\operatorname{tr}\left(\left[Y_{\mathrm{lmi}}\right] N\right)+\operatorname{tr}\left([N]^{T} Y_{\mathrm{lmi}}^{T}\right) \\
& \times[A][P]-[B]\left[Y_{\mathrm{lmi}}\right]+[P][A]^{T} \\
& -\left[Y_{\mathrm{lmi}}\right]^{T}[B]^{T}+\left[B_{w}\right]\left[B_{w}\right]^{T}<0
\end{aligned}
$$

subject to

$$
\left[\begin{array}{cc}
{\left[X_{\mathrm{lmi}}\right]} & {\left[R_{\mathrm{lqr}}\right]^{1 / 2}\left[Y_{\mathrm{lmi}}\right]} \\
{\left[Y_{\mathrm{lmi}}\right]^{T}\left[R_{\mathrm{lqr}}\right]^{1 / 2}} & {\left[P_{\mathrm{lmi}}\right]}
\end{array}\right]>0,
$$

where $N$ is a noise position vector, $\left[X_{\operatorname{lmi}}\right]$ and $\left[Y_{\mathrm{lmi}}\right]$ are the LMIs solutions, and $\operatorname{tr}($ ) denote the matrix trace.

3.2. Fuzzy Modal Controllers. The first step of this approach consists in the fuzzification of each controlled mode $\left\{X_{i}(t)\right\}$ in the fuzzy input. In this work, two-membership GBELL Matlab functions "positive" and "negative" are used. For these membership functions the relevance of each variable is given by

$$
\mu_{A}\left(X_{i}(t)\right)=\frac{1}{1+\left|\left(X_{i}(t)-c_{f}\right) / a_{f}\right|^{b_{f}}},
$$

where $a_{f}, b_{f}$, and $c_{f}$ are the parameters of the GBELL function.

The inference engine implements the "minimum" function $w_{j}$. Mahfoud and der Hagopian [21] presented fuzzy controller rules applied to flexible structures. These rules were used in the present contribution and they are presented in Table 3.

Finally, the control is obtained after defuzzification. This defuzzification requires the knowledge of the fuzzy output variables corresponding to the rules and the aggregation of these rules as well as the output membership functions. In
TABle 3: Fuzzy controller rules of Ayyub et al. 1997 [20] and Mahfoud and der Hagopian 2011 [21].

\begin{tabular}{llc}
\hline Rule & Condition & Decision \\
\hline 1 & IF positive displacement AND positive velocity & Action \\
2 & IF positive displacement AND negative velocity & No action \\
3 & IF negative displacement AND positive velocity & No action \\
4 & IF negative displacement AND negative velocity & Action \\
\hline
\end{tabular}

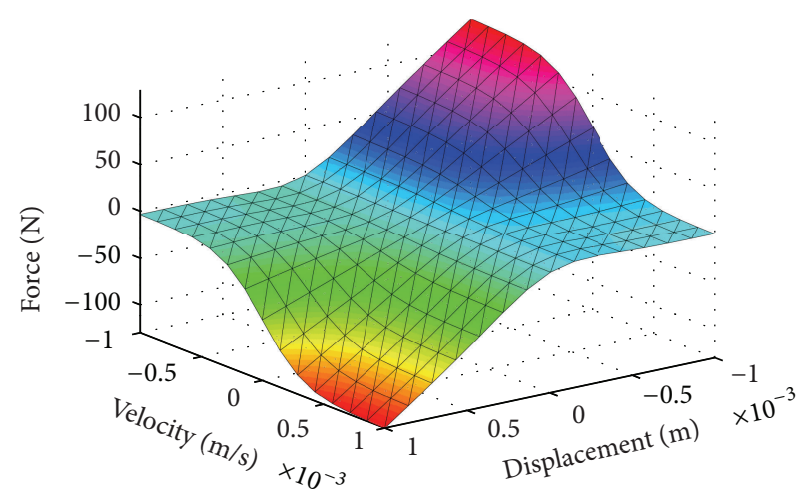

FIgURE 6: Control force-mode $i$.

this paper the Takagi-Sugeno method is used due to its good adaptation to controller real time computation. The membership functions for the four modes are similar and are presented in (14) $\left(z_{1}\right.$ corresponds to "no action" and $z_{2}$ to "action"):

$$
z_{1}=0, \quad z_{2}=\alpha_{i} q_{i}+\beta_{i} \dot{q}_{i}
$$

where $\alpha_{i}$ and $\beta_{i}$ are, respectively, the weights assigned to the displacement and velocity of the mode $i$, respectively.

The command force $F_{i}$ (Figure 6), for mode $i$, is given by the output of the controller and can be written as

$$
F_{i}=\frac{\sum_{j=1}^{2} w_{j} z_{j}}{\sum_{j=1}^{2} w_{j}} .
$$

\section{Numerical and Experimental Results}

Figure 7 presents the rotor test rig that was designed for the present research work.

Two situations were analyzed in terms of unbalance response. In the first case, the steady state was considered 


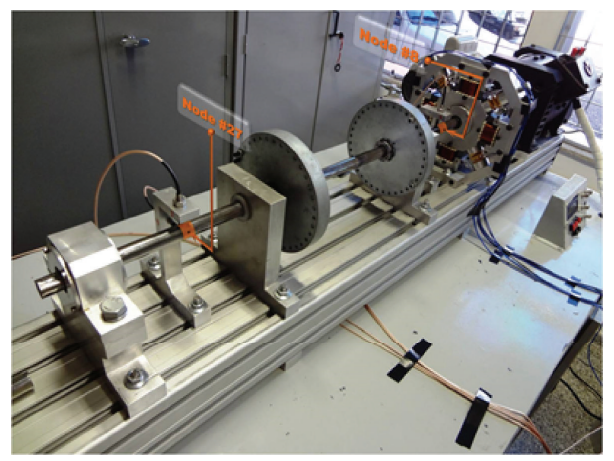

FIGURE 7: Rotor test rig.
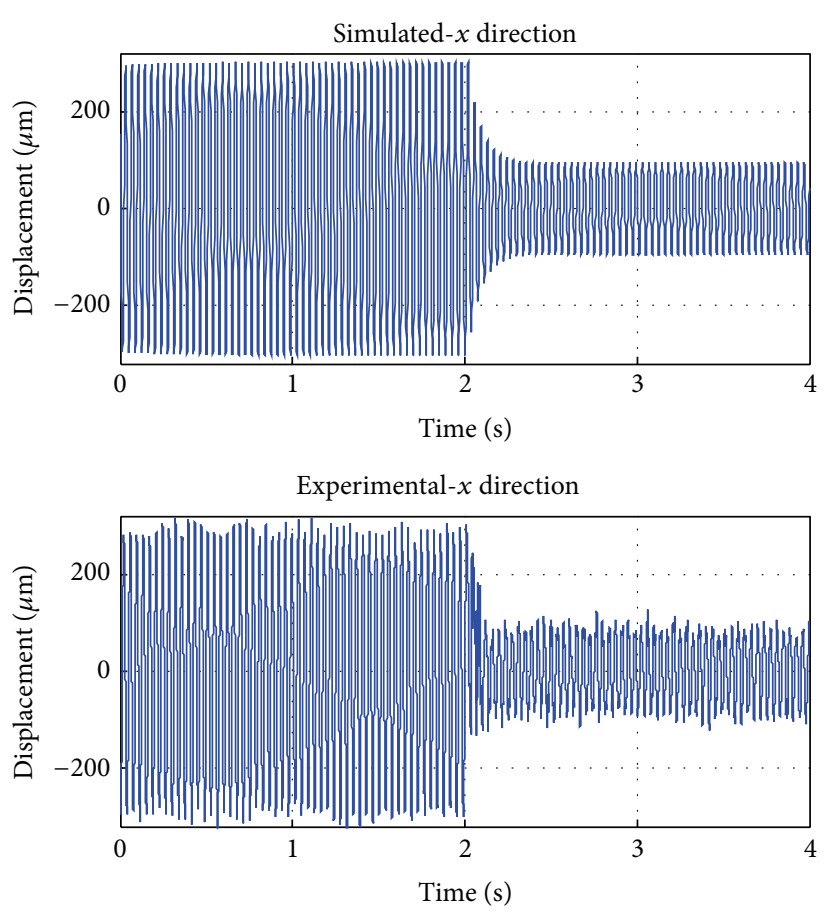
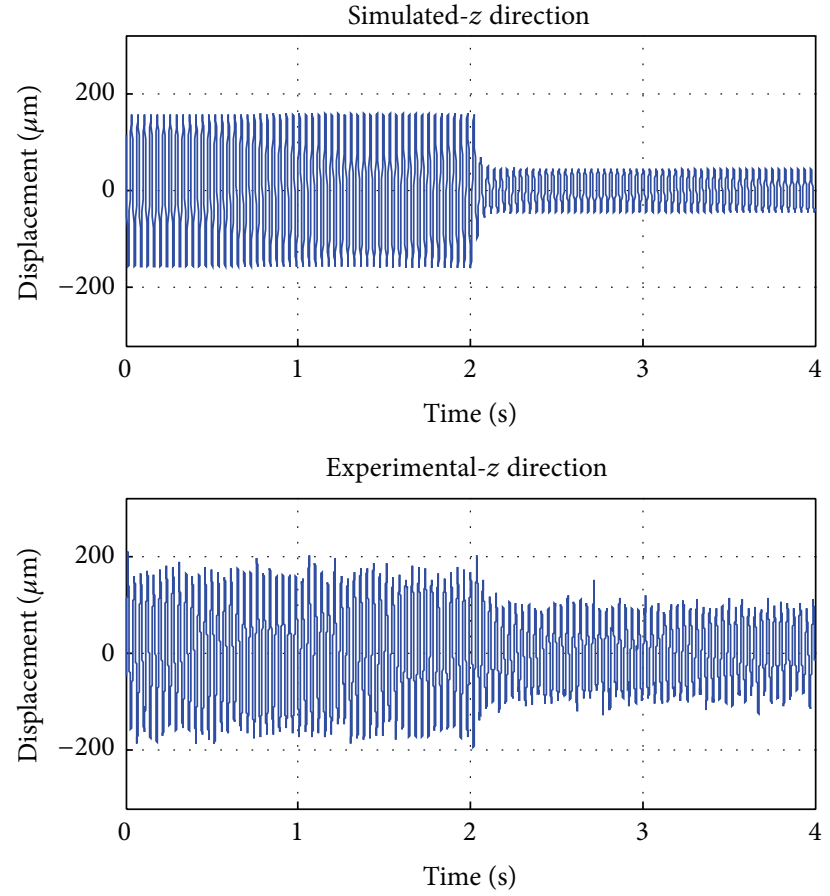

FIGURE 8: Unbalance response-node number 27-steady state-1600 rpm (LQR).

(the rotation speed is $1600 \mathrm{rpm}$ and the sampling time is $4 \mathrm{sec}$ ); in the second case, the transient response was studied (run-up test considering the rotation speed varying from $1450 \mathrm{rpm}$ to $1850 \mathrm{rpm}$ in $4 \mathrm{sec}$ ). The following sections present the obtained results for the numerical (simulated) and experimental tests. For both cases the presented results consider two control approaches, namely, the linear quadratic regulator and the fuzzy modal controller.

Sections 4.1 and 4.2 present the numerical and experimental results. The importance of the numerical tests is that the corresponding results are used to adjust the controllers (first guess of the control plant). Besides, the simulation model is required by the Kalman estimator to obtain the rotor displacement at the hybrid bearing position and the modal states. This data is necessary both in the solution of the actuator inverse model (electric currents determination) and in the calculation of the control efforts.
4.1. $L Q R$ Controllers. Figure 8 presents the unbalance response for steady state.

Analyzing the responses shown in Figure 8, it is possible to observe the control action on the system in terms of vibration attenuation. In the $x$ direction the peak-to-peak amplitude (experimental results) reduced from $610.20 \mu \mathrm{m}$ to $173.15 \mu \mathrm{m}$, while in the $z$ direction this reduction was from $349.20 \mu \mathrm{m}$ to $183.72 \mu \mathrm{m}$. These values represent, respectively, $71.62 \%$ and $47.39 \%$ reductions along the $x$ and $z$ directions, respectively.

Figures 9 and 10 present the electrical current used by each EMA, respectively, along the $x$ and $z$ directions.

Figures 9 and 10 permit observing the values of the electrical current required by the actuators. The control forces are sinusoidal and they are all attraction forces. Along the $x$ direction, for example, the positive part is attributed to EMA1 and the negative part is attributed to EMA2. The same 

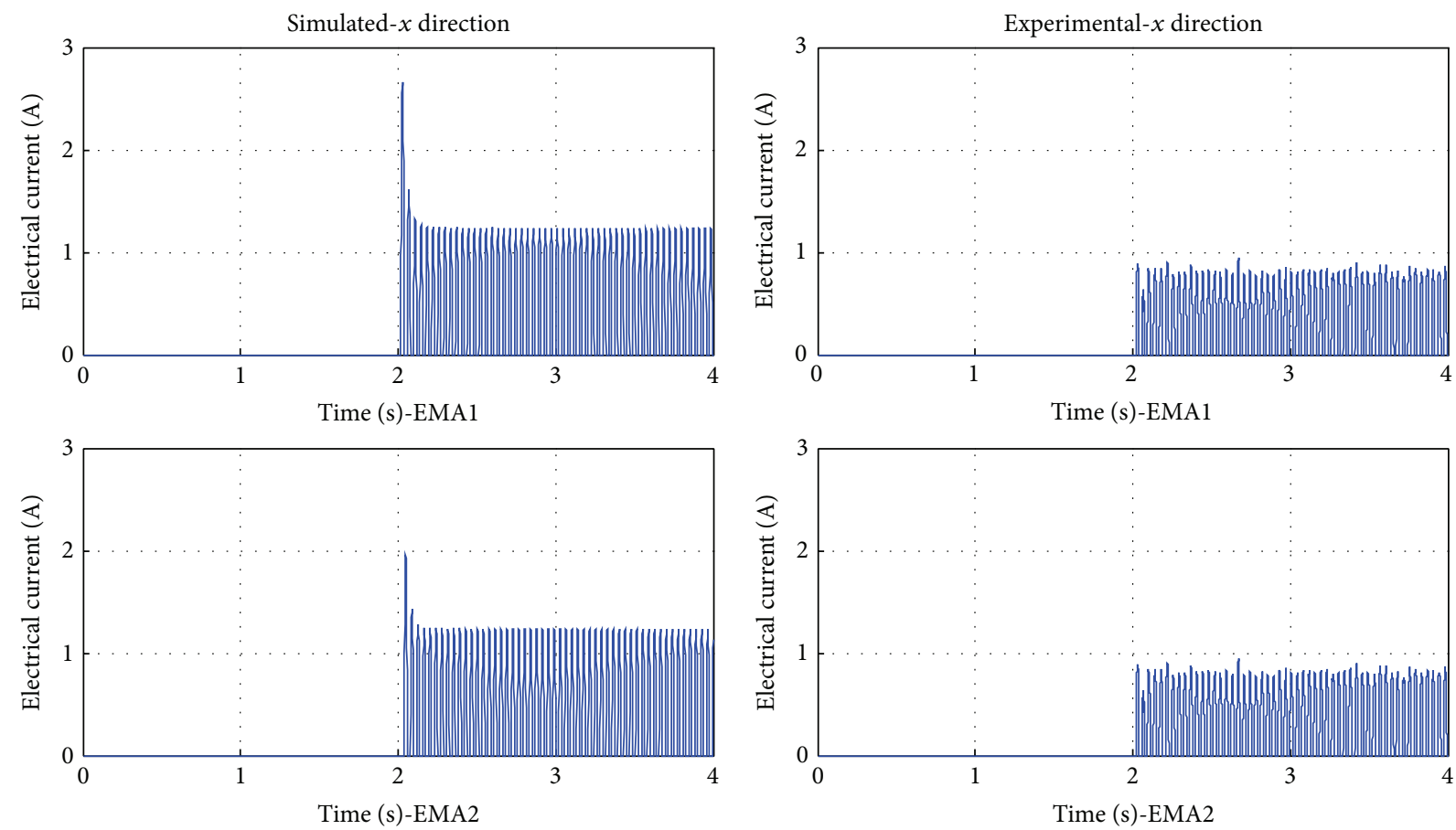

FIGURE 9: Electrical current-steady state-1600 rpm (LQR).
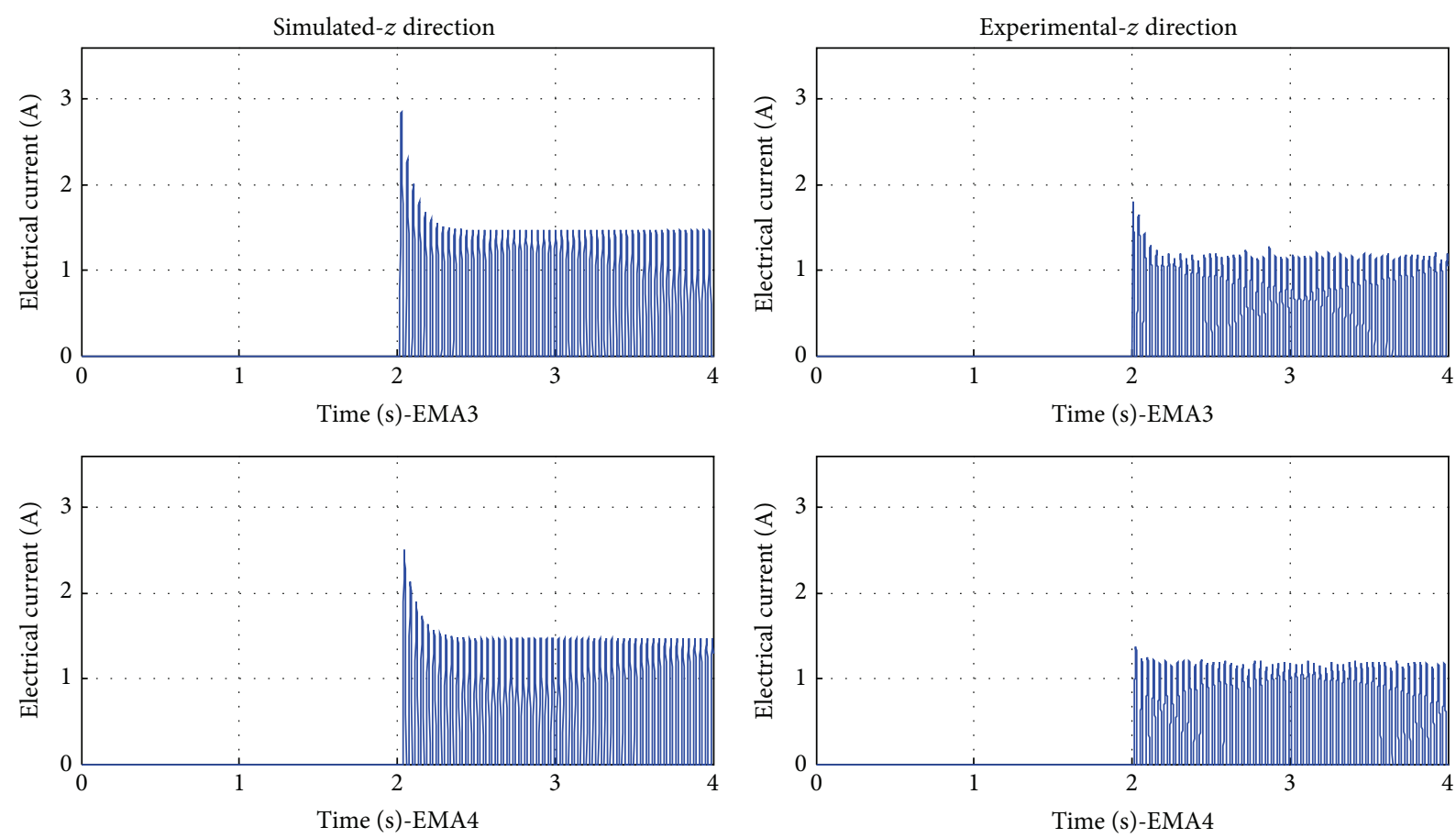

FIGURE 10: Electrical current-steady state-1600 rpm (LQR).

procedure is applied along the vertical direction (EMA3 and EMA4). For the $z$ direction higher electrical current is required, resulting, however, in a smaller attenuation as compared with the $x$ direction. As expected, the best values occur along the $x$ direction, since along this direction there is no influence of gravity.
Finally, Figure 11 presents a comparison of the orbits for the cases control-off and control-on; it is possible to see the reduction in the unbalance response of the system. Figure 12 presents the unbalance response for the run-up test.

Figure 12 shows the vibration attenuation when crossing the critical speed, along both perpendicular directions. 


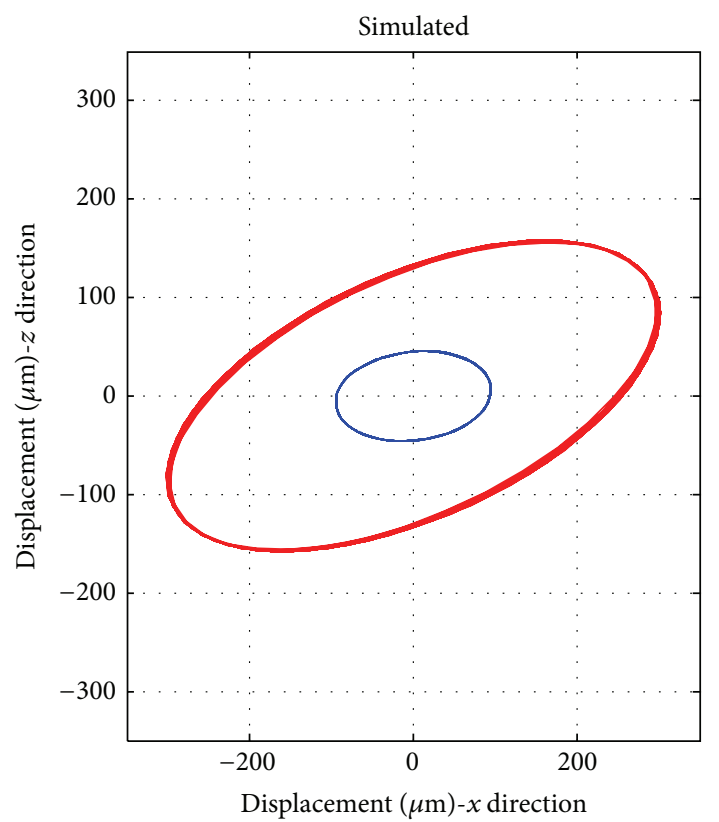

- Control-off -.. Control-on

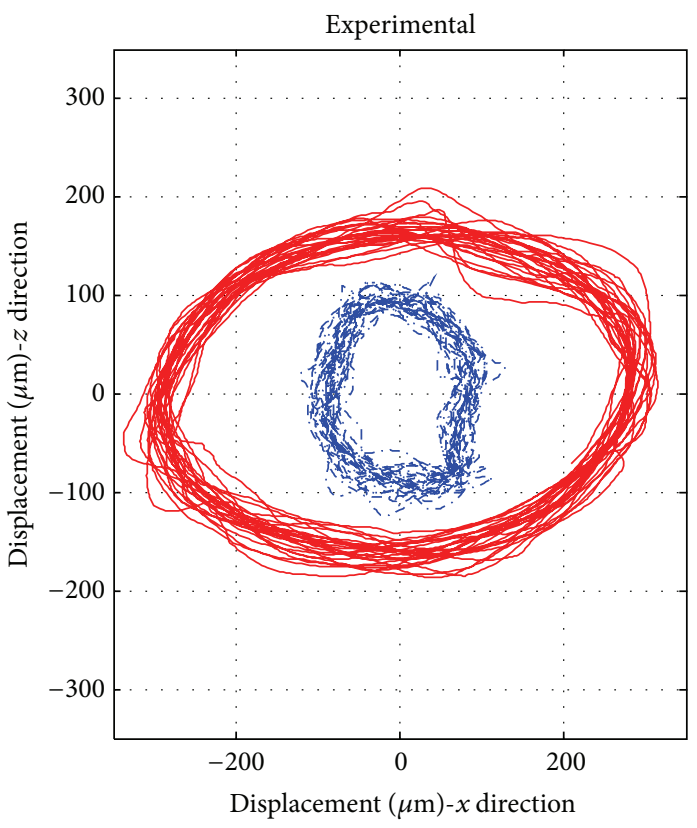

— Control-off

_.. Control-on

FIGURE 11: Orbits-node number 27-steady state-1600 rpm (LQR).
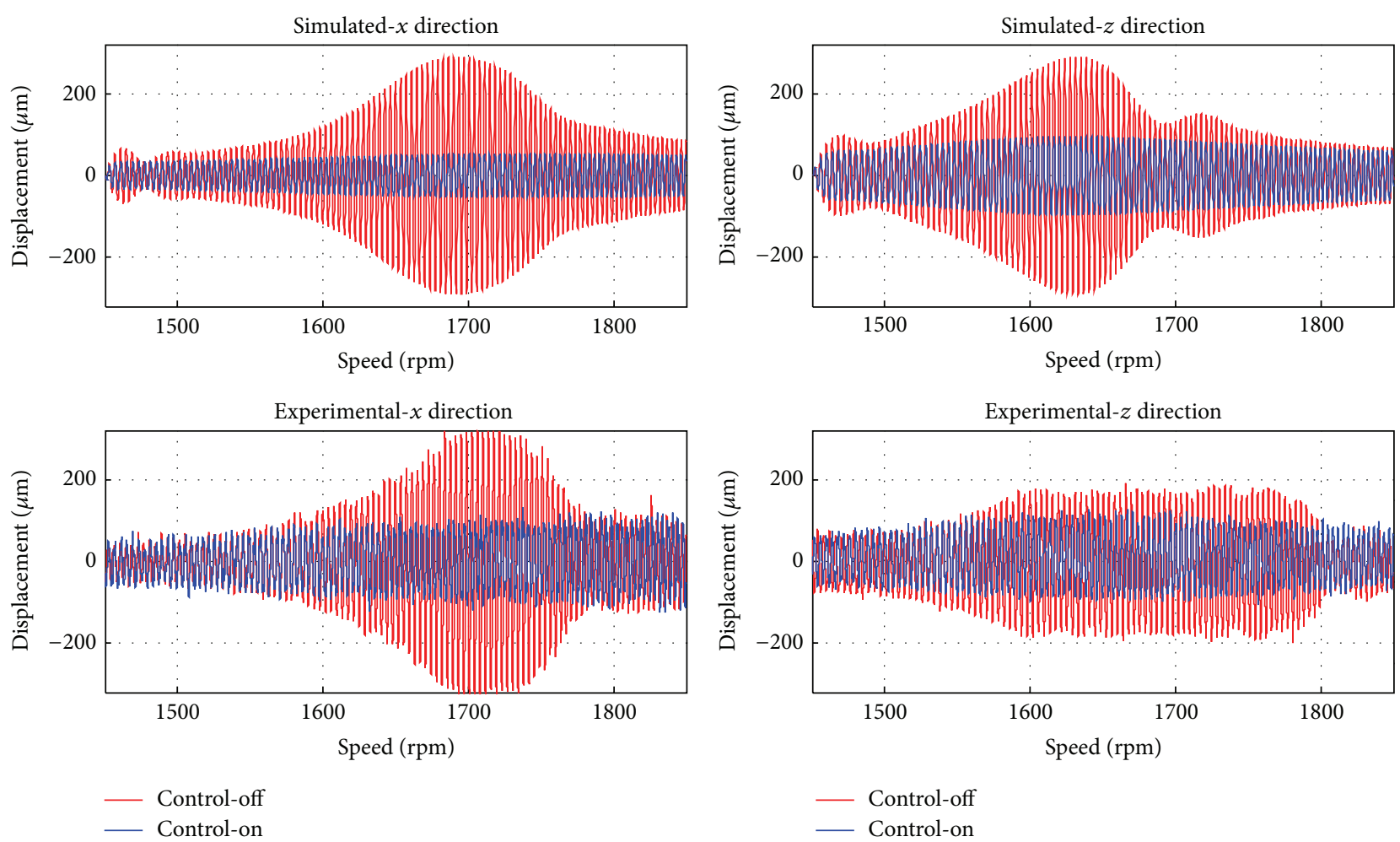

FIGURE 12: Unbalance response-node number 27-run-up test (LQR). 

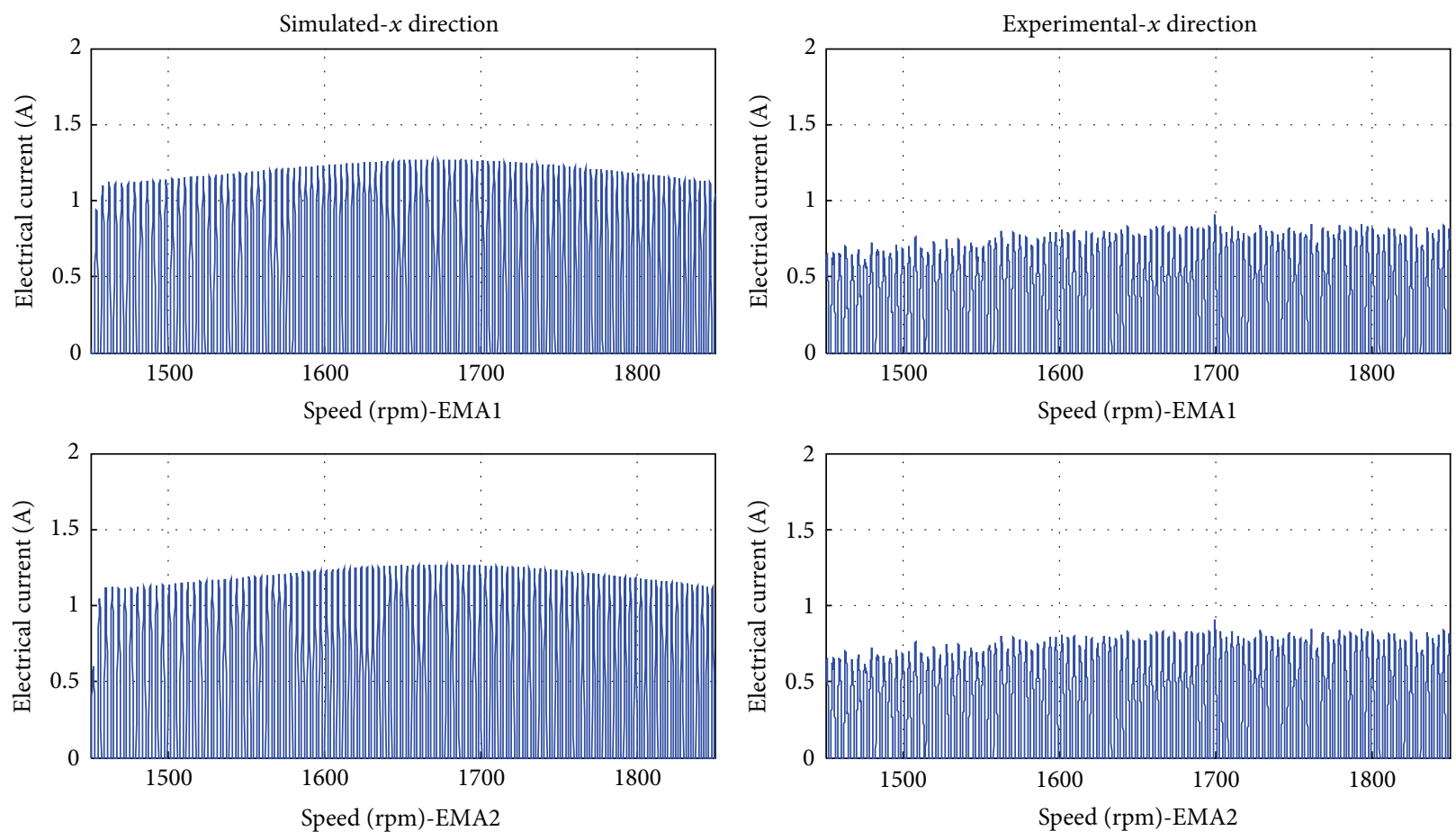

FIGURE 13: Electrical current-run-up test (LQR).
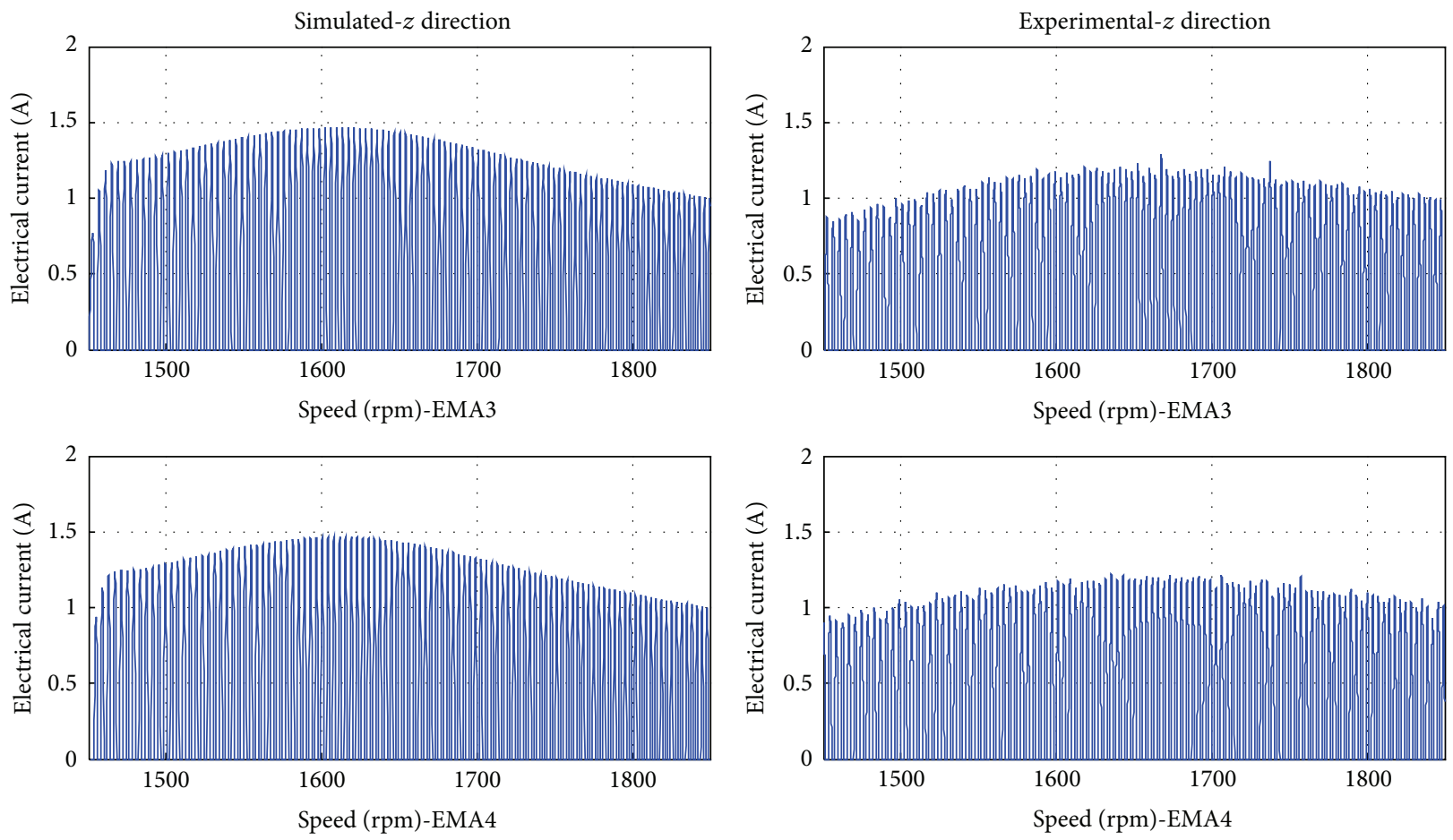

FIGURE 14: Electrical current-run-up test (LQR).

For the experimental case the peak-to-peak amplitude was reduced from $627.62 \mu \mathrm{m}$ to $209.30 \mu \mathrm{m}$ ( $x$ direction); along the $z$ direction the reduction was from $439.35 \mu \mathrm{m}$ to $233.35 \mu \mathrm{m}$. These reductions represent $66.65 \%$ and $46.89 \%$ reductions along the $x$ and $z$ directions, respectively.
Figures 13 and 14 present the electrical current used by the EMAs in the run-up test.

The behavior of the electrical current required by the runup test presents a similar trend as the one that was shown for the steady state response. 

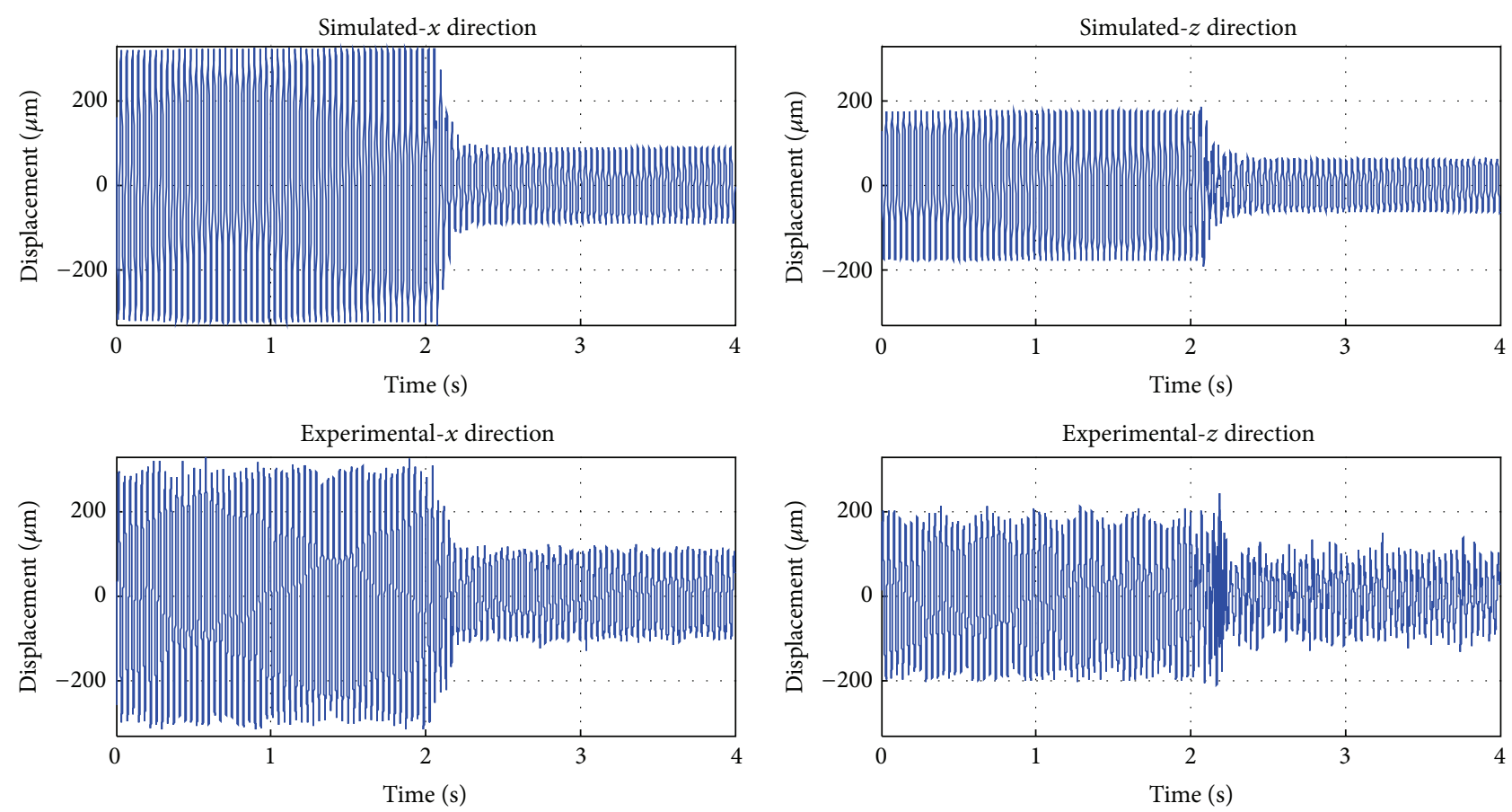

FIGURE 15: Unbalance response-node number 27-steady state-1600 rpm (FMC).
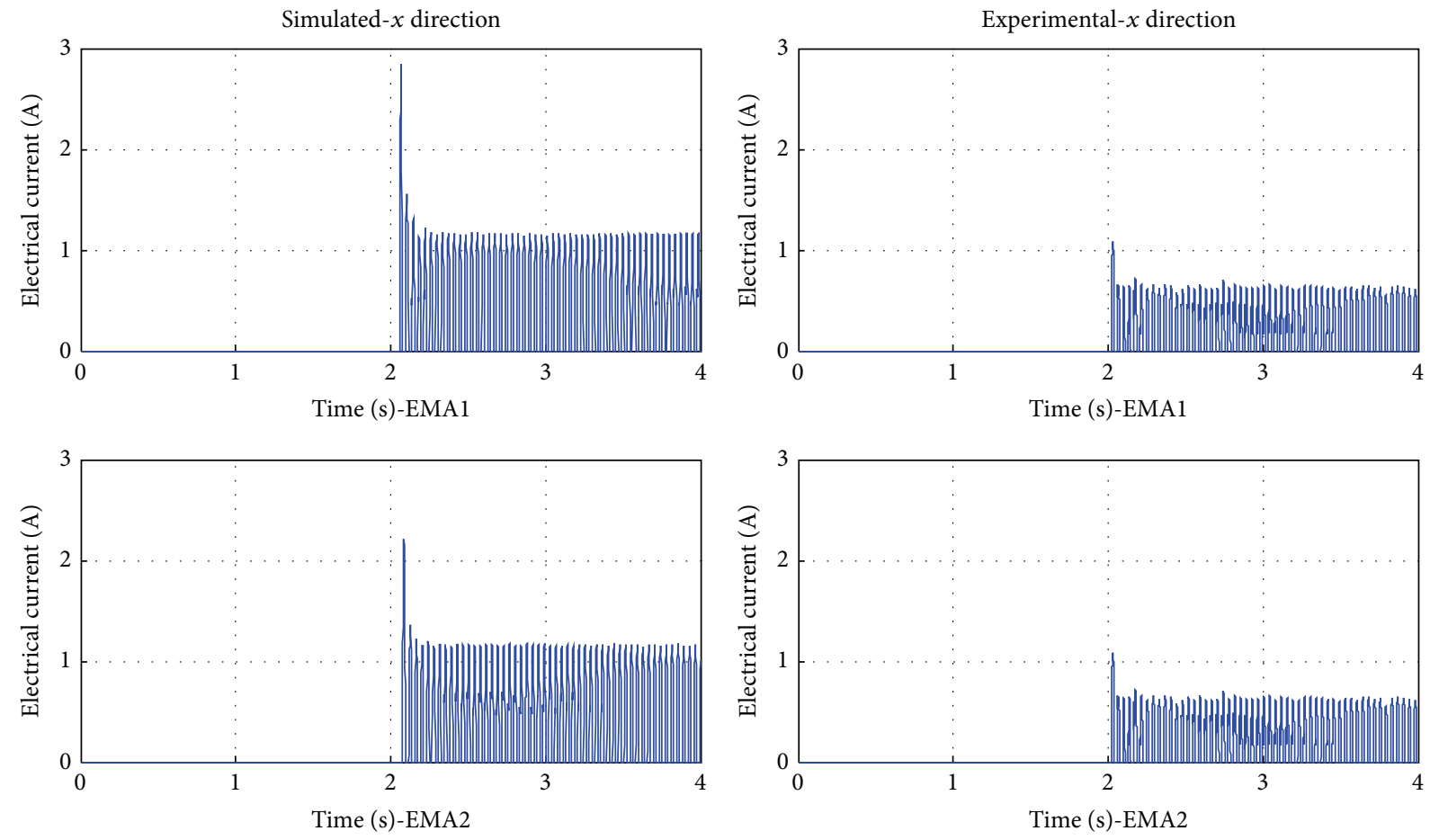

FIGURE 16: Electrical current-steady state-1600 rpm (FMCs).

4.2. Fuzzy Modal Controller. Figure 15 presents the unbalance response in the steady state using the FMC.

Figure 15 shows that the steady state response is significantly attenuated by using the FMC. The peak-to-peak amplitude (experimental result) was reduced from $609.8 \mu \mathrm{m}$ to $219.03 \mu \mathrm{m}$ along the $x$ direction and from $395.9 \mu \mathrm{m}$ to $217.47 \mu \mathrm{m}$ along the $z$ direction, which represents, respectively, $64.08 \%$ and $45.07 \%$ attenuations.

Figures 16 and 17 present the electrical current using by the EMAs. 

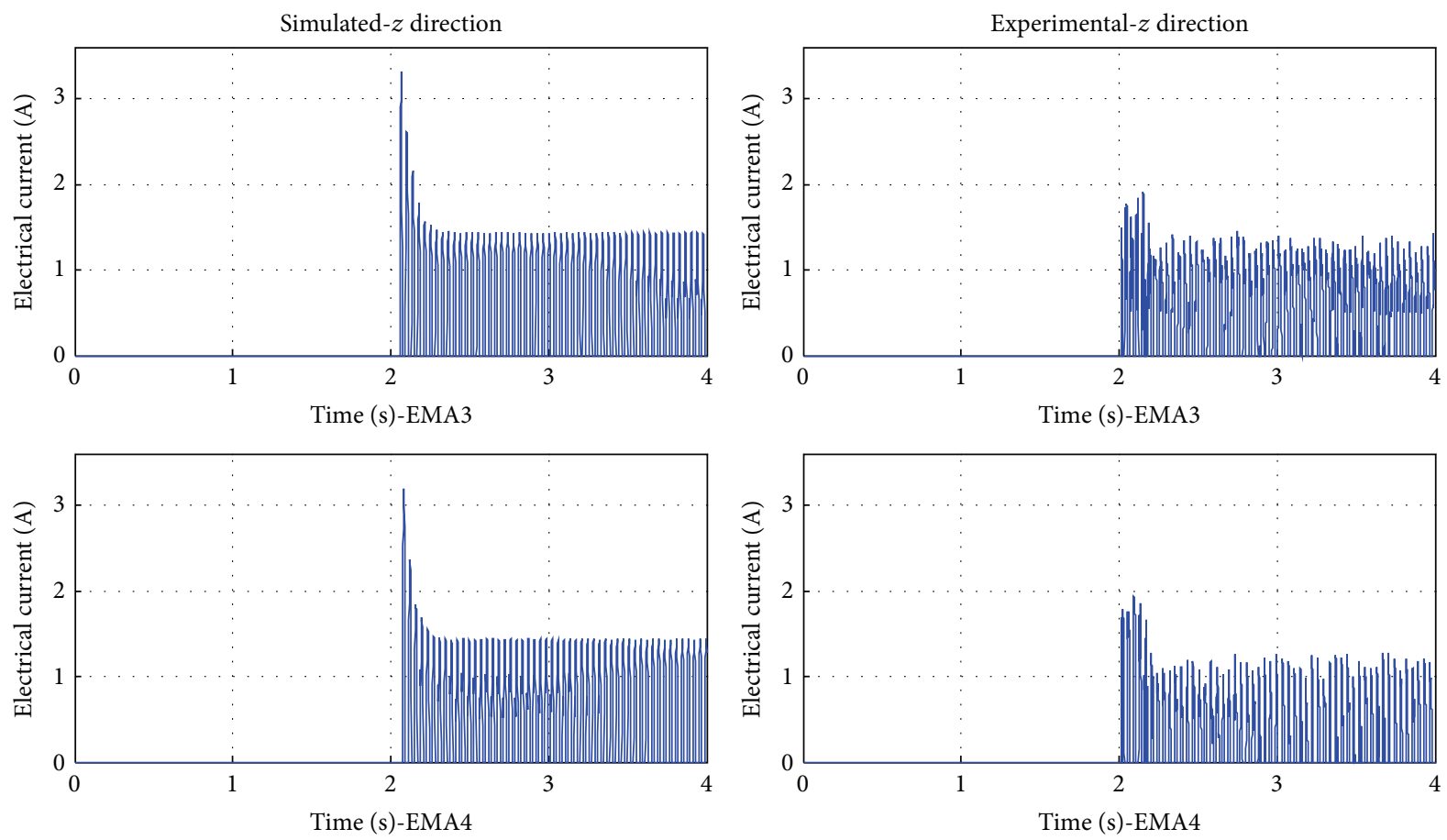

FIGURE 17: Electrical current-steady state-1600 rpm (FMCs).
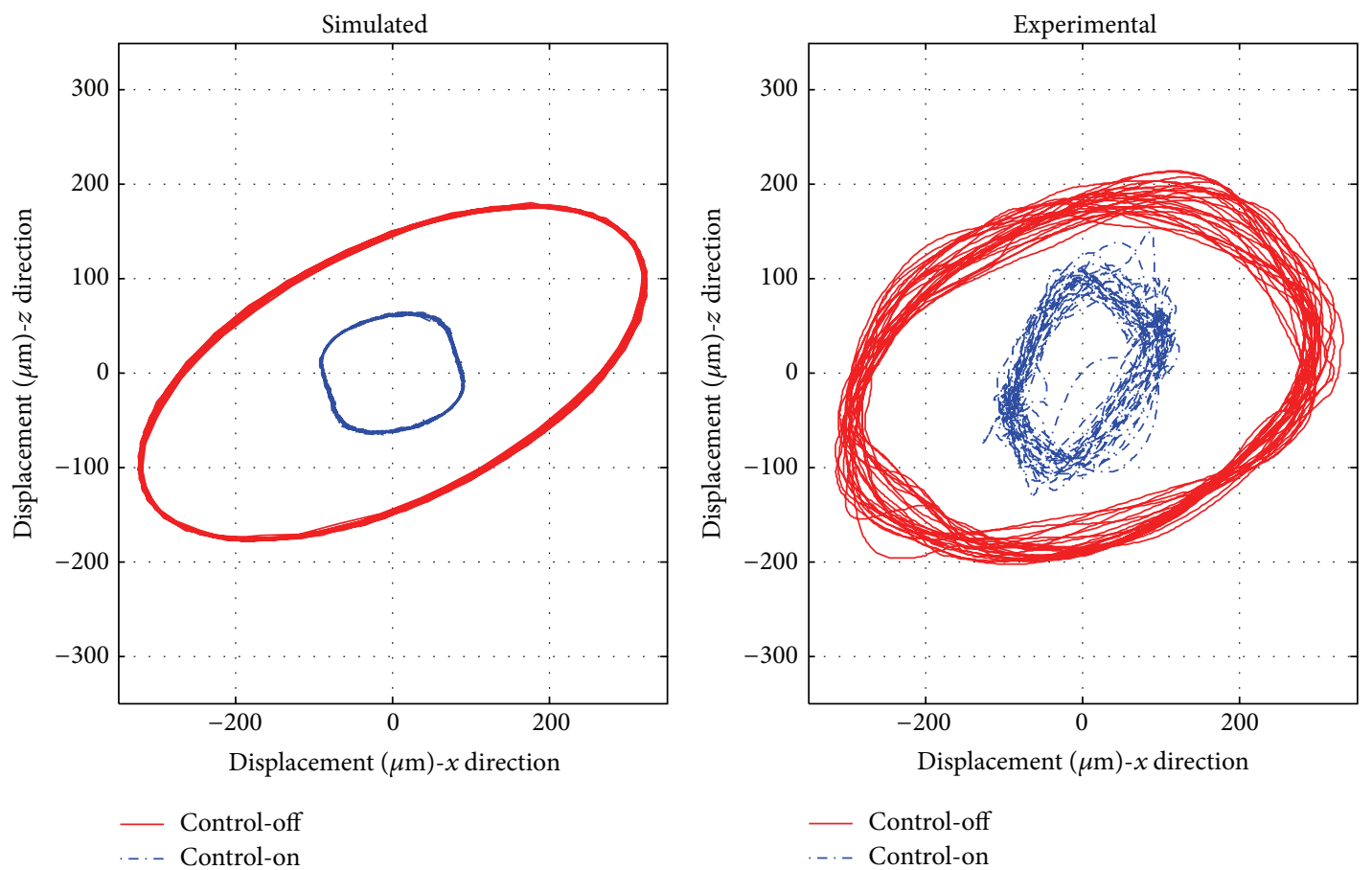

FIGURE 18: Orbits-node number 27-steady state-1600 rpm (FMC).

In this case, considering FMCs, the influence of the gravity (along the $z$ direction) was observed again. Finally, the orbits of the system (control-off and control-on) are presented in Figure 18.

Figure 19 presents the unbalance response for the run-up test by using FMC.
In the run-up test using FMC the unbalance response was reduced from $637.62 \mu \mathrm{m}$ to $330.02 \mu \mathrm{m}$ along the $x$ direction, while along the $z$ direction the reduction was from $439.35 \mu \mathrm{m}$ to $256.56 \mu \mathrm{m}$, which represents $48.24 \%$ and $41.60 \%$ attenuation along the $x$ and $z$ directions, respectively.

Figures 20 and 21 present the electrical current required by the EMAs considering the FMC. 

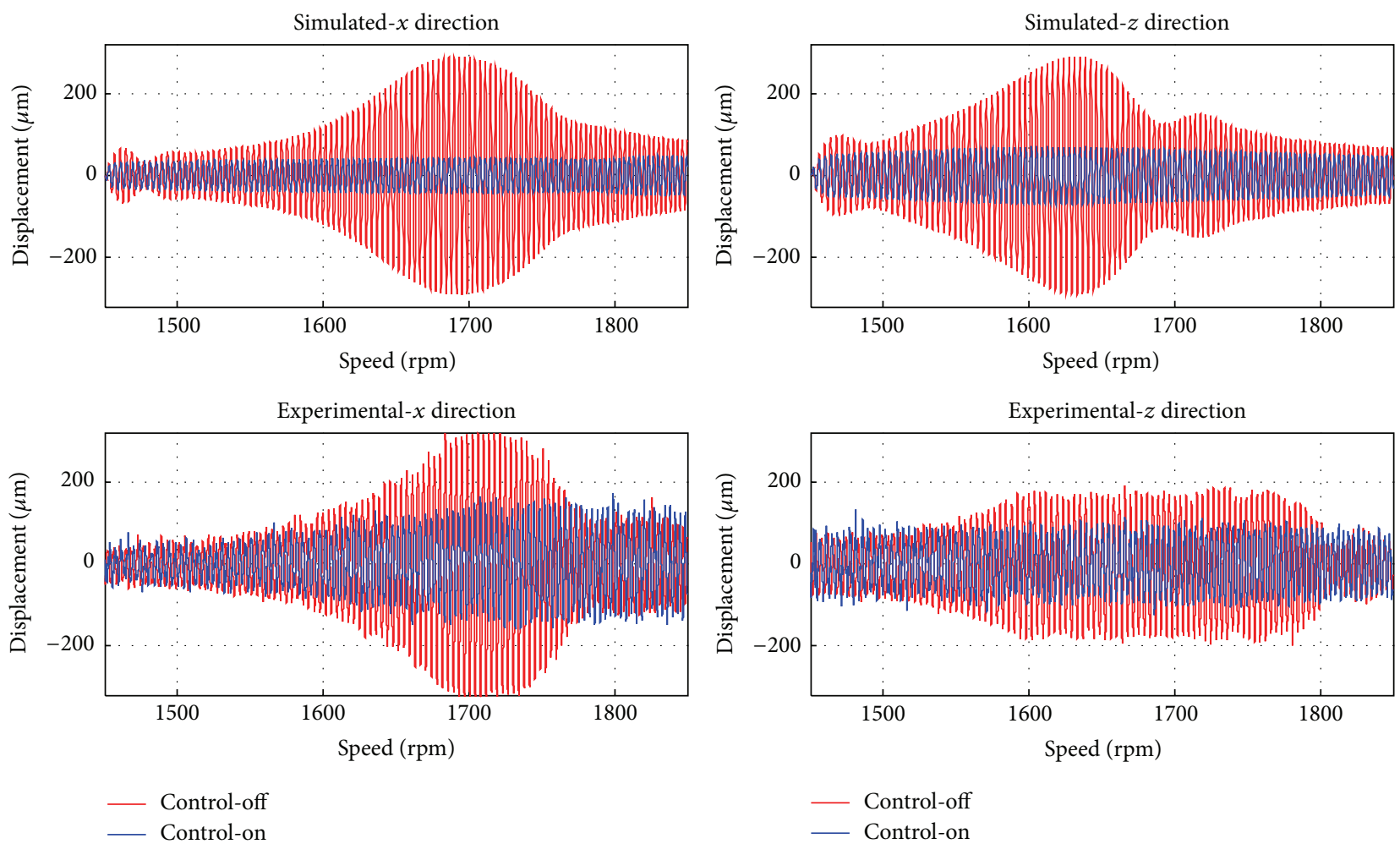

FIGURE 19: Unbalance response-node number 27-run-up test (FMC).
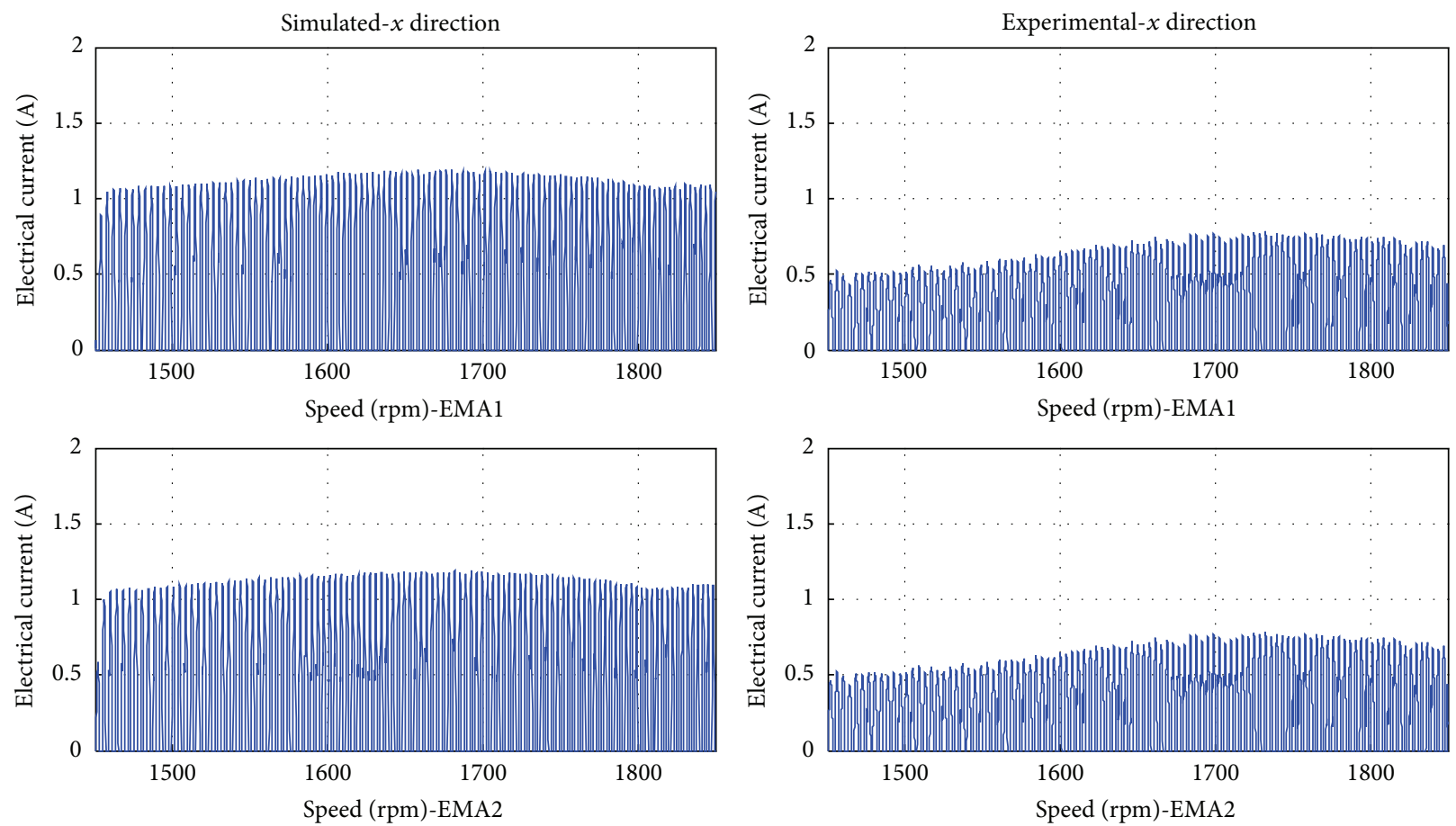

FIgURE 20: Electrical current-run-up test (FMCs). 

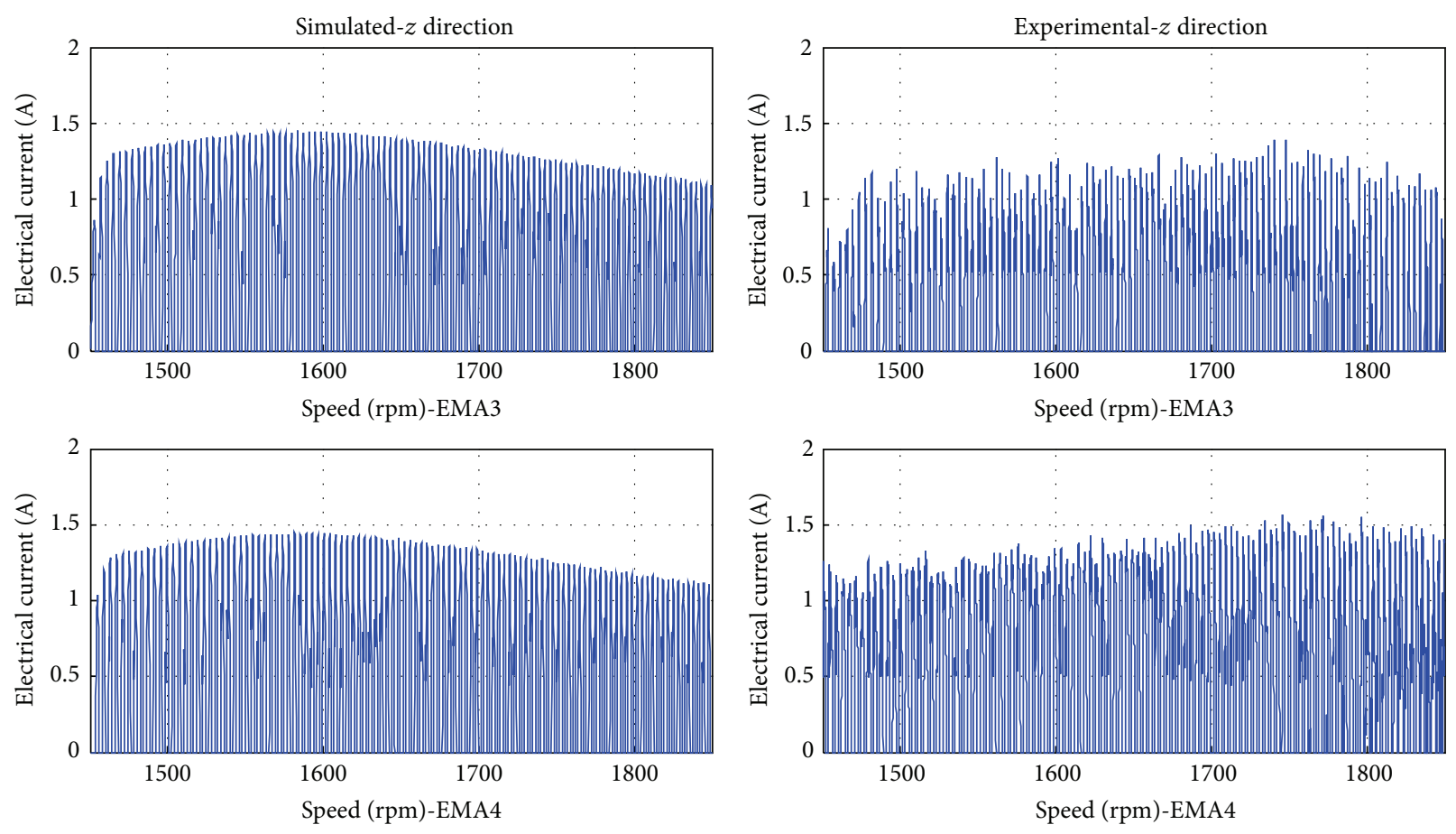

FIGURE 21: Electrical current-run-up test (FMC).

The same trends of the previous cases were observed in the run-up test by using FMC.

\section{Conclusions}

The most important contribution of this paper is that the control techniques were successfully applied to a complex rotor system (flexible rotor, electromagnetic actuators, and sophisticated controls) both numerically and experimentally.

Two approaches were evaluated for the control of rotating machines. The controller gains were determined by linear quadratic regulator (LQR) for the first case and fuzzy logic for the second case (fuzzy modal controller). Both approaches are shown to be efficient for the two scenarios analyzed (steady state for constant rotation speed and run-up), considering the unbalance influence.

The complete methodology was analyzed and illustrated both by numerical and experimental tests. The importance of the numerical tests is to use the corresponding results to adjust the controllers and the model of the system for experimental applications. Besides, the numerical results were presented to demonstrate that the designed controllers lead to satisfactory results for vibration attenuation of flexible rotors.

The experimental results demonstrated that both designed controllers (LQR and FMC) are efficient for vibration attenuation of flexible rotors by using electromagnetic actuators. The LQR controllers showed better results, since the attenuation level of the controlled system response was higher than the ones found for other control architectures. In the unbalance response (steady state and transient response) it was possible to observe a reduction of $71.62 \%$ and $47.39 \%$ in the steady state and $66.65 \%$ and $46.89 \%$ in the transient responses, respectively.

Another highlight is that the numerical and experimental results are quite close, despite the complexity of the systems analyzed. It is believed that even better results can be obtained provided that a better mechanical assembly of the rotating machine is assured, thus eliminating (or drastically reducing) the existing gaps. As for the adopted mathematicalcomputational model, its better fitting to the experimental behavior of the system should also contribute to better results.

Further research work will encompass uncertainty analysis of actively controlled flexible rotors.

\section{Conflict of Interests}

The authors declare that there is no conflict of interests regarding the publication of this paper.

\section{Acknowledgments}

The authors are thankful to the Brazilian Research Agencies FAPEMIG, CNPq, and CAPES for the financial support to this work through the INCT-EIE. The first author is also thankful to CAPES-Cofecub Project no. 673/10.

\section{References}

[1] S. Hurlebaus, U. Stöbener, and L. Gaul, "Vibration reduction of curved panels by active modal control," Computers \& Structures, vol. 86, no. 3-5, pp. 251-257, 2008. 
[2] S. Li, "Active modal control simulation of vibro-acoustic response of a fluid-loaded plate," Journal of Sound and Vibration, vol. 330, no. 23, pp. 5545-5557, 2011.

[3] M. Bratland, B. Haugen, and T. Rølvåg, "Modal analysis of active flexible multibody systems," Computers \& Structures, vol. 89, no. 9-10, pp. 750-761, 2011.

[4] F. Resta, F. Ripamonti, G. Cazzulani, and M. Ferrari, "Independent modal control for nonlinear flexible structures: an experimental test rig," Journal of Sound and Vibration, vol. 329, no. 8, pp. 961-972, 2010.

[5] P. R. Houlston, S. D. Garvey, and A. A. Popov, "Modal control of vibration in rotating machines and other generally damped systems," Journal of Sound and Vibration, vol. 302, no. 1-2, pp. 104-116, 2007.

[6] M. J. Balas, "Feedback control of flexible systems," IEEE Transactions on Automatic Control, vol. 23, no. 4, pp. 673-679, 1978.

[7] R. C. Simões, V. Steffen Jr., J. der Hagopian, and J. Mahfoud, "Modal active vibration control of a rotor using piezoelectric stack actuators," Journal of Vibration and Control, vol. 13, no. 1, pp. 45-64, 2007.

[8] H.-C. Yu, Y.-H. Lin, and C.-L. Chu, "Robust modal vibration suppression of a flexible rotor," Mechanical Systems and Signal Processing, vol. 21, no. 1, pp. 334-347, 2007.

[9] M. Malhis, L. Gaudiller, and J. der Hagopian, "Fuzzy modal active control of flexible structures," JVC/Journal of Vibration and Control, vol. 11, no. 1, pp. 67-88, 2005.

[10] J. Yao, Z. Jiao, D. Ma, and L. Yan, "High accuracy tracking control of hydraulic rotary actuators with modeling uncertainties," IEEE/ASME Transactions on Mechatronics, vol. 19, no. 2, pp. 633-641, 2014.

[11] A. B. Palazzolo, S. Jagannathan, A. F. Kascak, G. T. Montague, and L. J. Kiraly, "Hybrid active vibration control of rotorbearing systems using piezoelectric actuators," Journal of Vibration and Acoustics, vol. 115, no. 1, pp. 111-119, 1993.

[12] G. Schweitzer and E. H. Maslen, Magnetic Bearings: Theory, Design and Application to Rotating Machinery, 2009.

[13] H.-G. Horst and H. P. Wölfel, "Active vibration control of a high speed rotor using PZT patches on the shaft surface," Journal of Intelligent Material Systems and Structures, vol. 15, no. 9-10, pp. 721-728, 2004.

[14] N. Skricka and R. Markert, "Improvements in the integration of active magnetic bearings," Control Engineering Practice, vol. 10, no. 8, pp. 917-922, 2002.

[15] T. S. Morais, V. Steffen Jr., and J. Mahfoud, "Control of the breathing mechanism of a cracked rotor by using electromagnetic actuator: numerical study," Latin American Journal of Solids and Structures, vol. 9, pp. 581-596, 2012.

[16] J. der Hagopian and J. Mahfoud, "Electromagnetic actuator design for the control of light structures," Smart Structures and Systems, vol. 6, no. 1, pp. 29-38, 2010.

[17] B. Riemann, E. A. Perini, K. L. Cavalca, H. F. de Castro, and S. Rinderknecht, "Oil whip instability control using $\mu$-synthesis technique on a magnetic actuator," Journal of Sound and Vibration, vol. 332, no. 4, pp. 654-673, 2013.

[18] H. P. Viveros and R. Nicoletti, "Lateral vibration attenuation of shafts supported by tilting-pad journal bearing with embedded electromagnetic actuators," Journal of Engineering For Gas Turbines and Power, vol. 136, no. 4, Article ID 042503, 2013.

[19] E. H. Koroishi, J. Mahfoud, and V. Steffen Jr., "Active modal control of a flexible rotor using Electromagnetic Actuator (EMA)," in Proceedings of the 18th Symposium Vibrations, Chocs et Bruit, Clamart, France, July 2012.
[20] B. M. Ayyub, A. Guran, and A. Haldar, Uncertainty Modeling in Vibration, Control and Fuzzy Analysis of Structural Systems, World Scientific, 1997.

[21] J. Mahfoud and J. der Hagopian, "Fuzzy active control of flexible structures by using electromagnetic actuators," Journal of Aerospace Engineering, vol. 24, no. 3, pp. 329-337, 2011.

[22] M. Lalanne and G. Ferraris, Rotordynamics Prediction in Engineering, John Wiley \& Sons, New York, NY, USA, 1998.

[23] T. S. Morais, J. der Hagopian, V. Steffen Jr., and J. Mahfoud, "Modeling and identification of electromagnetic actuator for the control of rotating machinery," Shock and Vibration, vol. 20, no. 1, pp. 171-179, 2013.

[24] E. A. Johnson and B. Erkus, "Structural control with dissipative damping devices," in Proceedings of the American Control Conference, vol. 3, pp. 2463-2468, May 2002.

[25] B. Erkus and Y. J. Lee, Linear Matrix Inequalities and Matlab LMI Toolbox, University of Southern California Group Meeting Report, Los Angeles, Calif, USA, 2004. 


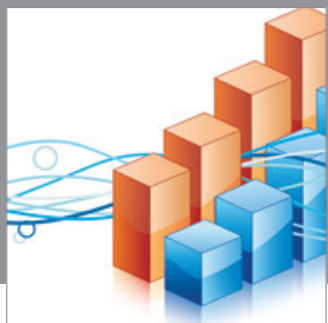

Advances in

Operations Research

mansans

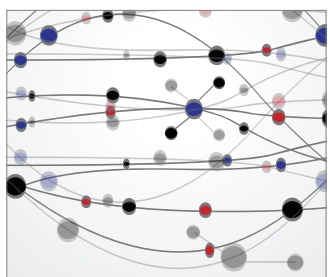

The Scientific World Journal
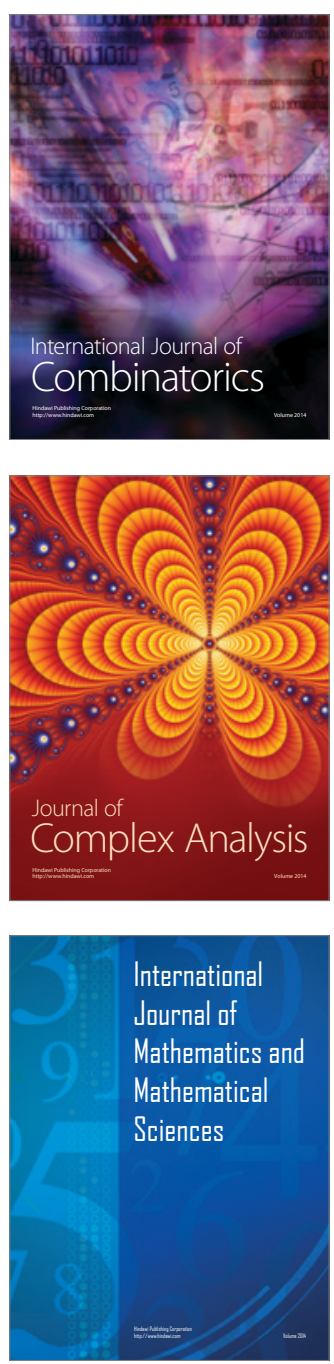
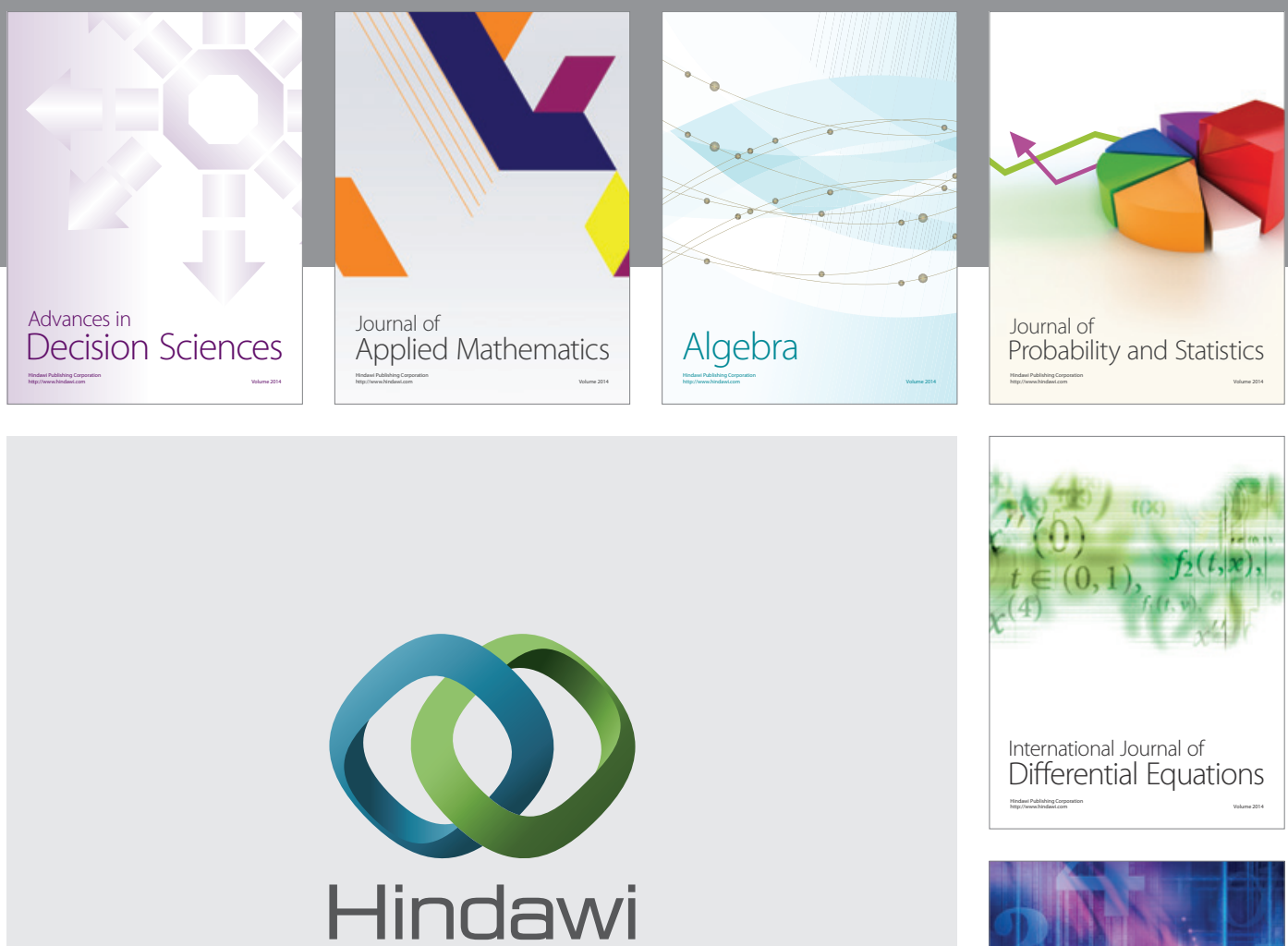

Submit your manuscripts at http://www.hindawi.com
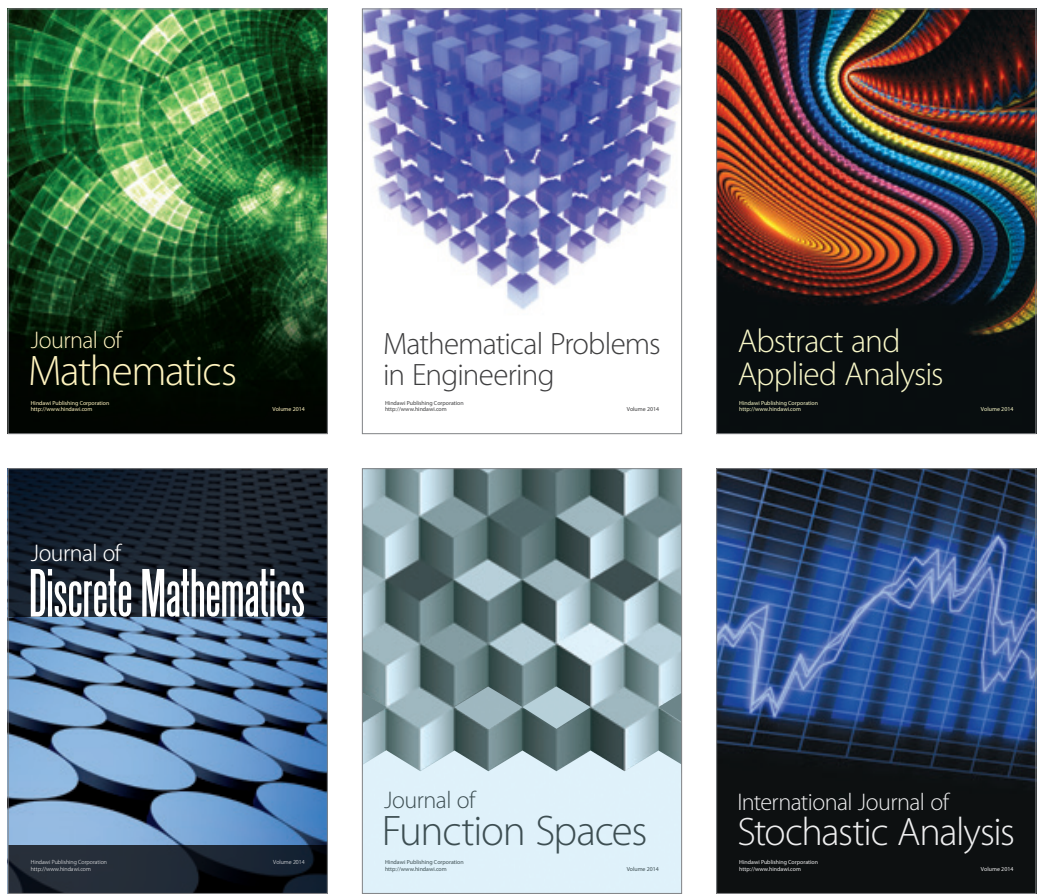

Journal of

Function Spaces

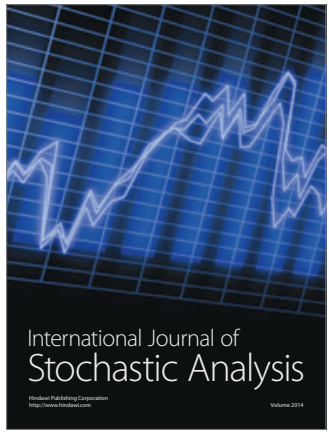

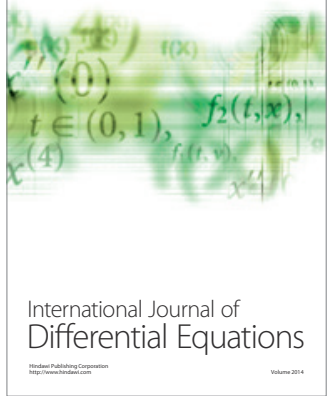
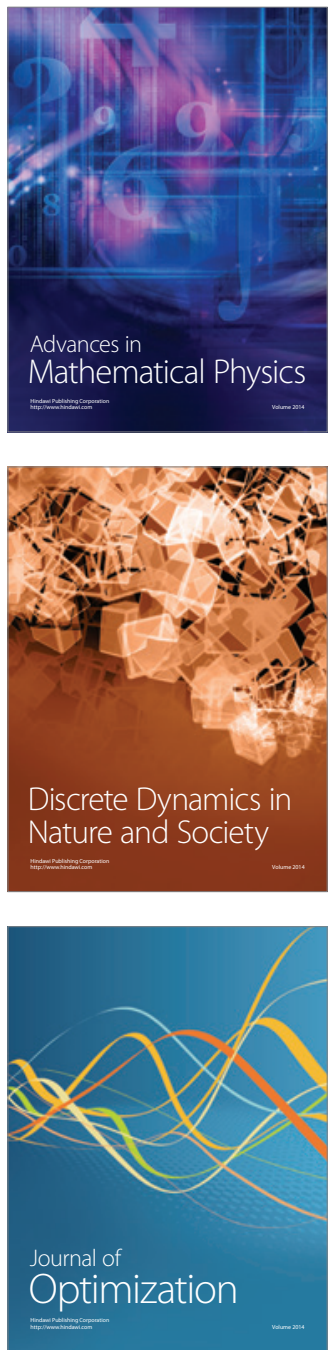